\title{
Magical Realism: The Magic of Realism
}

\author{
Ayyub Rajabi', Majid Azizi ${ }^{2}$, Mehrdad Akbari ${ }^{3}$ \\ ${ }^{1}$ Ph.D. Student of Persian Language and Literature. Arak Islamic Azad University, Arak, \\ Iran.Email: ayob.raiabi@gmail.com \\ ${ }^{2,3}$ Assistant Professor of Persian Language and Literature, Islamic Azad University of Arak
}

\begin{abstract}
In Magical Realism the elements of reality and imagination are so elaborately interwoven that the reader simply accepts them, in such a way that all artificial and imaginary incidents in the storyline seems completely real and natural. Considering the concept of Realism, it can be realized that literature aims to surrender itself to the real world and, by the means of imagination and imagery, balances the truth. Furthermore, realism admits that it owes a repayment to the real world, the world that it indisputably surrenders itself to. The results of this study indicated that, this art and the magic of Realism and reality have transformed Magical Realism into the most appealing and real type of Realism in such a way that, despite its magical and marvelous appearance, it is mostly acceptable and believable for the reader. Additionally, this kind of literary genre is more consistent with the principles of the school of Realism than any other, and it presents the mission of the Real author and his/her commitment to the community well and beyond reality.
\end{abstract}

Keywords: Imagination; Realism; Magical Realism; Knowledge; Reality.

\section{Introduction}

The term realism is derived from the root "real". In fact, realism is a viewpoint in which the objectivity is paid special attention rather than subjectivity. Some dictionary definitions for realism include: the belief in the existence of truth in generalities; the objects that we can percept have really an independent existence; the pursuit of truth and reality and especially in the art and literature; the image and visualization of the facts; the denial of illusions, and the emphasis on following the facts. Following these definitions, it turns out that Real (the truth) means the state and position of an object that is objective and is just the opposite of subjectivity. In other words, realism deals with issues that are tangible and out of mind and this point itself is very complex and contemplative. This is why sometimes realism is considered as an insincere and deceptive concept (Servat, 2002). For that, Naturalists, Surrealists, and even Symbolists and Romantics, consider themselves as Realists.

The point is that the term realism came from philosophical thoughts to literary criticism. This school claimed that "the percepts are objective and have a true existence beyond the mind of the percipient" (Parham, 1966). Consequently, there are various interpretations of the term 'realism'. It is believed that one of the causes of different interpretations of this term derives from this source, meaning that the knowledge is not a fixed concept and is constantly evolving and transforming. According to these transformations, the concept of truth can also be variable and changeable:

(C) AesthetixMS 2020. This Open Access article is published under a Creative Commons Attribution Non-Commercial 4.0 International License (http://creativecommons.org/licenses/by-nc/4.0/), which permits non-commercial re-use, distribution, and reproduction in any medium, provided the original work is properly cited. For citation use the DOI. For commercial re-use, please contact editor@rupkatha.com. 
“...the interaction between reality and imagination is the basis of the identity of literature. Wallace Stevens repeatedly addresses it in the subtle movements of that eternal equation. He believes that reality is not what it is. It is a combination of many facts that can be divided into them. No truth is a mere truth, and no one is universal in itself; the interplay between things makes them fruitful" (Grant, 2016).

Philosophical literature and sociology also considered the truth as a criterion for knowledge. They do not recognize the concept of truth as permanent and eternal, rather as the adaptation to the reality system of true existence. In other words, it can be said that the subject of knowledge is, in fact, human being plus the existence that both are changing and challenging. For this reason, the subject of knowledge (human) and the theme of knowledge (environment) are both changing and transforming. Inevitably, the relation between them which is knowledge cannot be fixed, too. As a result, the truth that is the trait of knowledge cannot be a fixed and definite quality. As the eternal existence is in the process of transformation, the truths also change. Therefore, it can be concluded that the truth is both broad and changeable due to social conditions and time. On the other hand, considering it as a simple case can also lead to anti-reality. In literature, the objective image of life is not realism, because the image of something that is observable through eyes only reflects the external aspect of the phenomena and, ultimately, transforms into a soulless photography:

"The goal of Realism is to search and express the real qualities of everything and the internal relations between a phenomenon and other phenomena. Realist literature does not study natural and social creatures as the single and self-consistent creatures, but treats them as endless chains of action and reaction" (Seyyed Hosseini, 2002).

As a result, from the perspective of literature, sometimes Romanticism is also realism. This general belief that in literature, Romanticism is anti-realism, is not readily acceptable, because in some situations, like the circumstances prevailing the Romantic era in the West, the romantic concept can also go beyond the apparent reality. In this regard, Dostoyevsky says

"A romantic person is one who has realized the falseness of the values of the eighteenth century. Values that in that century were against traditional classical values. The mission of his century was to deal with the new-structured religious and social faith with Byron and Lermontov kind of individual grief' (Parham, 1966).

Therefore, realism and romanticism are not two opposite schools, because romanticism through exploring the tangible world was the beginning of realism and instead of exact exploring and searching, replaced the analysis with integrated inspiration, and tended to explain the details. Nevertheless, it should not be concluded from this argument that there are no definite boundaries between literary schools, because, despite the problems of defining and specifying the scope of each school, it is possible to distinguish them from their dominant features.

So far as realism is concerned, we find that literature aims to surrender itself to the real world and, by the means of imagination and imagery, balances the truth.

"Realism, as the conscience of literature, admits that it owes a repayment to the real world; the world that it indisputably surrenders itself to it. So, realism is an artistic formula that with a certain understanding of reality tries to depict it" (Parham, 1966).

In this study, we consider magical realism, which is one of the branches of realism, against realism itself. By examining them, we seek to find the true connection between the schools of realism and magical realism. Indeed, the main purpose of this study is to find out if the nature of 
magical realism is the result of the magic of realism? That is, if the style of realism has created a magical realism by the means of a series of special features?

Based on the argument above, the following questions are put forth.

\section{Research Questions}

1. Does the magical state of realism increase or decrease its value?

2. Why do not the writer and characters of the story have any doubts about the reality of the story and its events?

3. Why does the writer of such works insist on the reality of characters and its incredible incidents?

4. Regarding the nature of the school of realism, which seeks to depict the ugliness of the society to reduce its suffering, does magical realism also have such a function?

5. How does the acceptance or rejection of magical realism affect the process of the story and its characters?

\section{Hypotheses}

1. The art and magic of the school of realism in its most complete and mature form, forms magical realism.

2. Magical realism and its beliefs are vital for the characters of the story.

\section{Background}

The term magical realism was first used in 1925 by the German critic Franz Roh to describe a group of post-expressionist painters. But the use of this term as a literary school traces back to 1949, when the Cuban writer Alejo Carpentier used it for the first time in the introduction of his book The Kingdom of this World. However, some believe that the history of this school dates back to the works of Kafka (Trial) and Bulgakov (Master and Margarita) between 1928 and 1938, but its real beginning and peak is related to the authors of Latin America. Writers such as Carlos Fuentes from Mexico, Jose Maria Arguedas from Peru, Miguel Angel Asturias Rosales from Guatemala, and most famously Gabriel Garcia Marquez from Colombia, are the followers of this school. In Iran the signs of magical realism can also be found in the works of Gholam Hossein Sa'edi, Mahmoud Dowlatabadi, Monir Ravanipour, Yousef Alikhani, and Reza Barahani.

\subsection{Magical Realism}

Since the 1980s, terms such as "magic realism", "magical realism" and "marvelous realism" have become so common and at the same time ridiculous terms. These terms are apparently composed of contradictory words. A form that shows the relationship created between these mutually exclusive terms is compulsory and obligatory. In recent years, of the three terms mentioned above, "magical realism" has become the most common term. What a narrative method offers, in fact, is a way of exploring different types of reality-based approaches in Western philosophy, embodied in many post-colonial and non-Western fictional works like the works of famous writers such as Gabriel Garcia Marquez. So far, no writing style has been so popular among ordinary readers, but what concern the critics and writers is that this term has diminished to an "obscure cliche" (Ann Bowers, 2014). 
The school Magical realism can be defined in two ways: 1) It can be considered merely a technique in telling the story, and 2) a method for narrating a story based on a particular attitude towards reality. According to the above-mentioned definitions, this school is not merely a technique, but rather a kind of belief in reality, a reality that is more complex and mysterious than what appears in the first place. In fact, this school is a mixture of reality with legendary elements and dreamlike and imaginative events, as well as myths or folklore. Based on this definition, in this school, unrealistic events occur in the context of a story that seems real, but these events may only seem strange, unrealistic or abstain from the reader's point of view. For the author and the story characters, these events are not beyond the scope of probabilities. This marks the boundary between magical realism and other storytelling styles. In the review of the history of the storytelling, we find that the events that seem real and the events that originate from the mind and are improbable have different definitions such as myth, fables, romance, social realism stories, science fiction, and fantasy stories. In magic realism, there is no boundary between imagination and reality, and real elements combine with fictional elements and become realistic. The elements of fiction appear in most stories, but the mere existence of fictional elements in the story does not allow the story to be considered as magical realism. Magical realism, creates the possibility of occurrence of an unrealistic phenomenon in the context of reality which "does not fully belong to the realm of imagination and not to the realm of reality and experience, but it has an independent feature." Mirsadeqi, 1998)

The emergence and overgrowth of this school in Latin America is related to the sovereignty of suffocation and the long repression of colonial governments and domestic self-dictatorships, the studies of western anthropologists about the Indian culture and myths, the great desire of this people to narrate the historical events and the pressure of all these events on the nation and the writers that ultimately were not allowed to express the reality freely. All these factors led to the development of a particular kind of realism (Dad, 2006). Therefore, this kind of expression can be considered as a special way of the school of realism, which the Latin American authors have chosen to do in conscious literary activity in order to awaken public thought.

Of course, this school is considered to be a special school specific to the Third World. Also, it is an exploration of the distant relationship between the primitive minds of these nations that are completely alien to Western culture. This school is involved with the native myths that are manifested in the realities of Latin American life. It has created its own world; while being specific to each nation, its joint effects may also appear in the future.

\section{The Components of Magical Realism}

In the magical realism style, the elements of imagination and reality are so combined, ultimately creating a kind of story that does not resemble any of its original elements. This combination is so elaborately performed that all of the fantastic imaginary events in the storyline seem real and natural, and the reader easily accepts them. Thus, magical realism is a combination of the two elements of imagination and reality, in such a way that it is difficult to distinguish and isolate them.

The components of magical realism in all the stories of this style are not the same, because in one story some elements may have more effect, and in others they may be less or non-present at all. The components that appear in most magical realism stories are as follows: 


\subsection{Ambiguousness}

In the narrative structure of such stories, the story elements are in a state of ambiguity, and the author makes a vague image in order to integrate the real and the supernatural world. For example, the vagueness of the names of individuals or time and place are in a mysterious state. In fact, this dichotomy is one of the most important features of the magical realism stories. "Authors who write in this style include heterogeneous scenes in the form of contrasting scenes such as rural and urban, western and native, real and imaginative, natural and supernatural as intertwined elements "(Mirsadeqi, 1998). For example, in the story of Azadaran-e Bayal, Bayal is the name of a region in which people's dilemmas are manifested in illusory and imaginative spaces. In fact, Bayal is a symbol of the world that Sa'edi portrayed in a shadow of ambiguity.

\subsection{Characterization}

In the magical realism stories, we see that the writer uses characterization in order to show its story real, and through objectifying some factors, tries to achieve this goal. In fact, to make imaginative elements seem real is the basis of magical realism stories. The characters of such stories are representative of the archetypes of the same land that show the collective unconscious in the sequence of the story with different titles. In the character analysis of such stories, most characters are dual, sometimes moving from the real world to the imaginary world or vice versa, without amazing themselves or the audience. In fact, "this dual characterization enables the writer to impose strange and imaginary events on the subject of the story in order to add to its imaginative state" (Nikoubakht; Ramin Nia, 2005).

\subsection{Making Tangible}

In magical realism, events occur as if they are in the real world. For this reason, the acceptance of characters and events is very common to the audience. In fact, in these stories phenomena are not imaginative and subjective, but they are concrete and objective, and the balanced coexistence between reality and magic is completely felt. In this style, the writer tries to describe unusual and strange events with a reality-based statement and avoid a threatening tone. He never tries to investigate or explain the reason for incredible events. Events and characters live in both real and supernatural world, and they do not get excited when moving from this world to the other. This is why in the works written in this style, on the one hand, there can be no distinct boundary between the real and the supernatural world, and on the other, the incidents seem believable and natural.

\subsection{Symbol and Myth}

Another component of the magical realism is the bold effect of national and local myths. In fact, the myth revolves around some extraordinary events and supernatural deities, and from these symbols and myths, people create creatures beyond the scope of ordinary imagination and reason. As a result, the symbolism that often occurs in these stories can also be the cryptic representation of thoughts and indirect criticisms of the political, economic, and social atmosphere governing the writer's community. For example, "cow" is the symbol of fertility in mythology, and in a village it is a medium between the earth and man. This myth has long been the symbol of fertility. "This myth is so strong that in the Avesta's Gathas, some of the clauses begins with the swear to cow"(Al-e- Ahmed, 1965). A mouse is also the symbol of destruction. For example, in the Azadaran-e Bayal, a mouse is depicted as destruction 
"the Bayal, its roads and farms is filled with mice. Wherever you go a mouse takes his head out of the hole and watches you. How big they are, they are rude and nosy and poke their nose everywhere they are" (Saedi, 2012).

\subsection{Metamorphosis}

One of the aspects of the magic is "metamorphosis". Regarding the magical realism, when aperson's identity changes from a higher position to a lower one, this event seems to be very common to the reader or observer. The reason is that, in the ancient myths and stories, such events have always existed and the audience encounters these events with previous background. For example, in the Qur'an and other religious books, the story of the miracles of the prophets is mentioned. This makes the audience easily accept the concepts of magic. In the story of Azadaran-e Bayal, when "Mash Hassan" loses his cow because of a severe grief, he suffers from an inner transmutation, so that he considers himself a cow: "As he was chewing he said: I am not Mash Hassan, I am a cow, I am Mashadi Hassan’s cow" (Saedi, 1391, 106).

\section{Magical Realism and the Magic of Realism}

In the definition of magical realism, we referred to two categories of imaginary and real elements. These two categories are easily recognizable for all human beings. In fact, the distinction between imagination and reality should be viewed from two different perspectives: 1) the audience, which is in the form of a reader in these stories, and 2) in film and painting as a viewer), from the perspective of the writer (creator) or the characters of the story. If we look at the subject from the viewpoint of the reader, we understand that what may be imaginary in a culture or a historical period may appear quite natural and real in other cultures and other periods. From the perspective of audience, these two categories of imaginary and real elements are definitely mutually exclusive, otherwise magical realism has no longer any meaning. If we look at this subject from the perspective of the writer or the characters of the story, it is understood that elements such as magic, angel, dream, soul, etc., which the audience consider unrealistic, are not created by the mind of the writer, but rather, besides being a part of the world of the story's characters, is also a part of the real world. In fact, the audience may have doubts about the reality of the elements of the story, or consider them as real, but the writer (creator) and his characters have no doubt about the real nature of these elements. In magical realism, the writer shows the reality by illustrating and describing the elements in the story and the magical and supernatural behavior of the characters which is apparently the real.

The writer does not analyze the characters of the story rather, by intertwining daily, historical, popular beliefs and times, creates a multidimensional picture of reality. Interestingly, the audience is not surprised by the unusual events that occur during the story. On the one hand, the author expresses reality, and on the other, by putting together imaginary and real elements, attempts to induce the elements as real to the reader. He does not express the truth or falsity of the events, and this makes the audience feel the author, and the characters of the story believe in their statements.

In this part, the questions raised for this study are explored. First, we will discuss the syntax of the two terms "magical realism" and "magic of realism". The term "magical realism" is a combination of the noun plus adjective that represents realism in a supernatural way, while the term "magic of realism" is a combination of a possessor and a possessive and expresses the properties and function of realism. Therefore, these two terms represent two separate concepts and thus it is incorrect to use them interchangeably. "Realism means the explicit and complete expression of 
individualities, so, the contract, imitation, and any kind of school, is the target of realism" (Grant, 1996). As we know, the perspective of realism, changes in the stages of meta-realism or surrealism. According to the followers of this style, unconscious contents, everything that passes through the minds of a person (if it is written before thinking), words that come out spontaneously, and the dream are all parts of the basis of surrealism. In surreal methods, abnormal properties attributed to common objects, or objects and concepts that are apparently unrelated are put together. Surrealists consider real human activity as the dreamlike activity of the inner voice of the unconscious world. They believe that many human thoughts and imaginations are not expressed because of being bound to ethics and society or politics, and inevitably, these imaginations are driven deep into the unconscious mind. Such thoughts and desires often appear in dream, jokes and the words that unconsciously slip out of mouth. The surrealist style agrees with the clear and honest expression of such thoughts, imaginations and desires. One of the confusions in understanding the magical realism lies in its coincidence with surrealism, because there are similarities between these two movements. The surrealists aimed to depict the hidden mental aspects of life in art. After the war, they sought new things and tried to "harmonize contradictions and conflicts" (Ann Bowers, 2014).

"The surrealist writer is not inspired, but inspires. His image does not represent any subjectivity or sensibility. It creates the mindset and stimulates sensitivity. The opposition of the contradictory concepts and words is to break the deductive aspect of the mind and to save the imagination"(Bigsby, 2016).

To answer whether the magic of realism increases or decreases its value, firstly, it is imperative to review the value of the realism school. As we know, the value and position of the realism school among other schools is that it emphasizes reality, and this is the distinguishing point of this style. But, what is real and what is unreal in this style is debatable. Looking at the form of magical realism, it becomes clear that it contrasts with realism, because the motto of realism is reality and the motto of magical realism is magic in the cover of reality. However, in the epistemology and ontology that we will refer to shortly, we observe that realities vary in terms of individuals and situations. Thus, this relativity of reality makes us consider the imaginations of magical realism real in which the author himself also believes to be real, and has no argument over on whether they are imaginary. As a result, magical realism not only does not diminish the value of the style of realism, but also illustrates the power of realism, that how it depicts unrealistic events realistic so that the audience does not hesitate about it. Realism with magic in the first place can be spectacular and interesting, an exquisite question the exploration of which exploring it brings new and vivid image of reality, a reality that is more prominent than any truth, and conceals due to the severity of disclosure.

Magical realism is not a style or a literary school which has special authors who write along the lines of its framework, rather it is a part of realism and reality, based on the disadvantageous circumstances of life of which, man gets help from it. Hence, such works are not considered as magical or real. Therefore, it does not matter what that magic of thought is, and even how far it is from the wisdom and logic for other human beings. This is the influence of this belief and thought on people's life which is significant and causes them to endure suffering. The same thoughts that have become a part of the reality of life can be seen in folk superstitions and beliefs; for example, the omen of a sneeze before beginning a work or the evil eye that has had a great impact on public belief in life.

We need to discuss beliefs in order to figure out why the author and characters of the story do not have any doubts about the reality of the story. Most people in every field of social and 
occupational work try to apply their beliefs in life. The writers of such stories also emphasize on their beliefs because they believe them, and these beliefs are derived from the inside and the heart. The writer is not trying to create a magical realism story but expresses the real story which critics consider as magical realism. But from the writer's point of view, a real story is based on the real events, and because these stories are not artificial and arise from the writer's belief, the audience also inevitably accepts them as real and reads them without any doubt.

Moreover, writers who have some works in this literary style speak about their own living place or travel to such places. However, if such works were the result of the writer's mind, then there would be no need to travel and observe and emphasize on the reality of these works. The writers also did not need to deny something called magical realism.

The characters of magical realism are so artistic that they live in the realm of such amount of disappointment and have become so aware that as a descended angel try to return to heaven. An important point here proving that such works are realist is that the art of the characters of magical realism in reality is much higher than the writer's art, to the extent that they amaze the writer, the writer who finds writing about the lives of such people more interesting than creating such characters. So, instead of creating a character, s/he discovers them.

Regarding the nature of realism as a school, which seeks to depict the ugliness of the society to reduce its suffering, we need to know if magical realism also has such a function. It should be said that magical realism writers, like realists, are not just paying attention to good things, but try to portray the ugly issues of society as well. As a precise sociologist, they explore the underlying facets of social reality and reveal the moral corruption, types of exploitation, poverty, hunger, and inhuman relationships. The writers of these stories explore the bad and ugly aspect of society. They write about poverty, hunger, misery, depravity, lies, brutality, insult, violence, cruelty and oppression toward common people, and depict a true and realistic image of the community.

Accordingly, the common suffering of these people which drives from their collective minds undoubtedly is immediately acceptable. Therefore, no matter how amazing these stories are, the focus here is not on their disbelief, but it tells of their great suffering which demands profound thought. The reality begins from the description of what we observe but it does not remain and ends with it. The real truth is the mind and thoughts that make the life possible for human in all circumstances and take it forward. On the other hand, it should be considered that how to a person, this amount of poverty, death, famine and ruin is believable and tolerable. The human body will not tolerate this amount of pressure and collapse but what prevents it is his mind and thought, which are as much real as much his body. So, both the body and the mind try to survive and what the mind decides, the body accepts immediately to save itself. The magic of reality is like this too. If it does not believe such charming and captivating magic, the body would not tolerate this much pressure. Therefore, the magic of mind and thought make a reality that ensures the life of human beings with this amount of problems. The amazing magic is that the more poverty and misery it contains, the more real it is. From this perspective, such a magic turns out to be more realistic than any truth. The magic that the life and death of a nation depends on and the slightest doubt they have about its nature can lead to the destruction of these people. In other words, the more suffering and difficulties in a land, the more real the magic of realism seems. Sa'edi, in his book Ahl-e Hava, argues that Ahl-e Hava refers to anyone who is stuck in one of the winds, and the winds means all the mysterious, ethereal forces that are everywhere and dominate the whole human race. No one and no power can deal with them, and the human being is so impoverished against them that there is no way but sacrifice and loss. The winds are sometimes cruel, and everyone escape from them are. Sometimes they are merciful, and some 
people eagerly accept them. Winds are everywhere, in all the seas and in the lands, and they always seek a depressed and heartsick body. Wherever there is a lot of horror and violence, there is a lot of wind, in every corner that there is poverty the power of winds is more, too. So, even if we accept that there is a style with this title (magical realism), which, of course, has always been denied by the great writers of this style, there are striking works that accepted by people come from such a magic, the magic that makes the terrible condition of living in such impossible situations possible. With this explanation, it becomes clear that the reality of a work not only is not contradictory, but is more tangible and inevitable than any other reality. What reality you know that the life of a nation be dependent on? Regarding this that magical realism is actually realism and only its imaginative aspect is their distinguishing factor then, in terms of the fundamental nature that is the expression of the realities they are not different from each other.

Concerning how the acceptance or rejection of magical realism affect the story process and its characters, it should be mentioned that acceptance and rejection by the writer is meaningless because the writers of such stories are certain about the characters and the events of the story. Therefore, the story is accepted from the writer's point of view, but it is different from the perspective of the audience. The influence and acceptance of such stories varies according to the audiences, because they are not in the same spiritual, temporal, and spatial circumstances. The audience whose living condition is like the condition of the characters of the story can understand the story better and consider it closer to reality. The audience whose psychological and living conditions are not like characters of the story will find it as an entertainment and consider its reality imaginary. In fact, between the characters of the story and the audience, there must be a relationship based on the similarity, so that the audience can feel himself as the characters of the story. The passage of time has a great influence on the acceptance of such stories. The more the time of the story be far from the time of the audience's life, the less the audience understand the realities of the story, because culture and lifestyle are changing day by day, and today's life is certainly very different from 100 years ago. In this regard, Dostoyevsky implicitly states that "If we find the events of his stories "exceptional and unusual", this is our own problem not his. This is our perception of the concept of "probability and habit" that is wrong and nothing else" (Alot, 2014).

Another important point in magical realism story is the tone of narration. The tone plays a key role in such stories and expresses the tune of the speaker's emotions and reveals his intention and purpose. The tone creates space in the language, through which the characters identify themselves to the reader and communicate with him/her. In fact, the tone in the magical realism stories represents the extrasensory phenomena and mentality of the writer. Without requiring cause and reasoning, the writer uses the element of "exaggeration" in a particular way that the extrasensory and meta-reality phenomena happen so easily that the reader does not hesitate about their occurrence. With a close look at realism, we find that this school is the opposite of idealism, and the subject of realism and idealism is a topic that is discussed both in philosophical epistemology and ontology. Our argument related to the ontology, which observes the external world and seeks to prove the external or independent objective reality of the world without agent or subject. Accordingly, our knowledge is external or objective when it comes to aware us of the fact that its existence is not dependent on our perception and it is constant in nature; and because it seeks to prove our knowledge to the external world, it belongs to epistemology or the theory of knowledge. 


\subsection{Epistemological Realism}

\section{Sadeqi writes:}

"In the field of epistemology, realism refers to a view based on which the direct knowledge of the outside world is possible. In this type of realism, it is thought that the world of mind is in accordance with the outside world, and the mind is a passive mirror that represents the world just as it is. It seems that the mind separate from its owner's demands, frameworks, presuppositions, and social and historical knowledge during the cognitive process and carries out the task of cognition alone and correctly" (Sadeqi, 2010).

Parham says, "Another major aspect of the realist literature is to distinguish objective realities from the conventional conceptions or illusions that exist from reality" (Parham, 1966). In the study of this style, "reality" is the objective world independent of our existence, and "truth" is the adaptation of the mental image of the subject to the external reality. If the mental image of the identifier is based on "reality," it is honest and equivalent to the "truth," and if the mental image of the mind does not conform to the external reality, it is "false".

In epistemology, there is a serious struggle between realism and unrealism. The realist's approach to a skeptical person, i.e. the one who sees knowledge as relative, is that the knowledge of real and the outside world are possible. In fact, the conflict between the realists and the unrealists is not only verbal, but that a realist philosopher avoids nonrealistic and idealistic methods, and in this way s/he tries to make a realistic manner. Yet, from the epistemological idealist point of view, the characteristics consistent with the realism of understanding and knowledge and perception are rejected, and the definite existence of one thing cannot be understood. "Therefore, for different issues, scientific thought should have different philosophical factors, since the balance of realism and reasoning are not the same for all the concepts" (Bashlar, 2004).

External objects have two positions and in the final analysis of the truth they have two directions: one from the aspect of existence, which is the same as effectiveness, and the other from the aspect of essence, which is the same as ineffectiveness. However, something that obscures the knowledge of man is the same essence that lacks the external effects of the object. As a result, the obtained knowledge is conceptual, that is, the science in which the nature of external reality represents to us, not its existence. In this position, the basis for the acquisition of a particular knowledge in man is the isolation of the existence from the essence. So, in the magical realism, we see that in the works created in this style, individuals and objects are revealed on the basis of their actual essence. Of course, this knowledge of nature can vary from person to person, and each one takes a different conception of objects or individuals, and exhibits in their works. In fact, the real understanding of the nature of living and non-living creatures varies by the amount of reasoning and thinking, and the type of individuals' thoughts.

\subsection{The Ontological Realism}

The ontological basis stands on two questions. 1) What is existence?, and 2) What things exist in the universe? By using ontology, we can separate real beings from imaginary ones. The science of ontological realism is based on the fact that there is a genuine real world apart from our imagination. Accordingly, ontological realism is exactly the opposite of skepticism and idealism.

Realism has a structural understanding of causation, and does not consider the theory of causal ordering sufficient to explain the phenomena. From the perspective of realism, instead of asking what is causing something, it is better to ask what produces something and what mechanism will lead to an empirical order (Chalbi, 1995). 
Two forms of magical realism, which include ontology and epistemology realisms, can be distinguished from one another. The magical realism of ontology can be called a realism, the source of which its sources are the beliefs or rituals of the cultural context in which the text is set. For example, in the book The Kingdom of this World by Alejo Carpentier, there is a character called "Macandal", who has the ability to transform voluntary and even transforms to an animal. Macandal is in fact the historical character who led the rebellion of the slaves in Haiti and the novel has been written based on him. As Carpentier says, "however, Macandal lived in the United States, and these powers were given to him, the powers derived from the faith of his contemporaries, who, with this magic, sparked one of the strangest and most wondrous rebellions of history" (Carpentier, 2011). The idea that he possesses magical powers, such as transformation, is adopted by the Carpentier. It traces back to the belief of Haitian people who believed that man is able to change himself voluntary and become an animal. In other words, the magical realism of epistemology is inspired by sources for its magical realism- based components that are not necessarily consistent with the cultural context of the story or the writer. In fact, there is a similar difference between folklore magical realism (like magical realism of ontology) and virtuosic magical realism (like epistemological magical realism) in which magical realism derives from a particular folkloric tradition or from the diversity of traditions and makes a special narrative.

Hubert Lampo, a Flanderian writer, is a good example of epistemological magical realism. As he admits, "he was interested in using the techniques of magical realism to express the Belgian mood and also be part of a larger literary movement" (Ann Bows, 2014). He collected the aspects of magical realism from many sources, especially from the mythology of Rome and Greece. While it is argued that the mythology of Rome and Greece has influenced Western European culture, this is far from the historical and geographic point of view. In addition, this argument for this claim that Lampo's magical realism is predominantly rooted in Flanderian folklore, which also has German root, is not convincing. Of course, there is an assumption that the division of magical realism into ontological and epistemological categories is also problematic because it leads to inappropriate conclusions. This means that the writer can only be the creator of one of these two. Especially, this has deceptive effect on the fact that the writer of the ontological magical realism should not use this narrative method for literary testing or for intellectual reasons. In other words, it is as if the writers of ontological magical realism create the magical realism story because they automatically write that way and cannot get away from their thought while writing. Gabriel Garcia Marquez is a good example of the falsehood of such a hypothesis. When he talks about his works, he takes on the ontological position and emphasizes his belief in Latin American mythology: "I am a realist writer ... because I believe that in Latin America everything is possible, everything is real" (ibid, p. 143). At the same time, he expresses his epistemological position based on his knowledge of literature: "I believe that what we need to do is to promote literature to a condition for reality that can provide something new to the universal literature" (p. 143). John Locke also explains a theory of language in a research on the power of human perception (1690). He connects it with sensory influences and dependent on nature:

"If we consider how our vocabulary depends on a lot of sensible concepts to common sense, then perhaps it may lead us to the root of all our conceptions of knowledge ... and I have no doubt that if we could find their root, in all languages we would encounter the names that imply things (objects) that our intellect identifies them as lacking root in tangible concepts" (Grant, 2016).

In the magical realism stories, we find that most writers, relying on psychological ideas, are trying to represent the unconscious of individuals, and by psychoanalysis of the characters, reveal the 
influence of the society's circumstances on the mental state of individuals, which itself is a representation of events.

\subsection{Magical Realism and Dream}

In the study of magical realism, we see that this style combines reality with imagination like dream and daydream. Humans, observe events that happen during sleep the occurrence of which is impossible during awakening such as flying, which is normal and natural during sleep, and the viewer will not be surprised to see his own flying, while is impossible for a human to fly in the real world. Magical realism is likewise and through imagination, it reaches to infinite stages. In fact, daydreaming creates a world of supernatural thinking. By seeing images that are outside the real world, human beings realize that there is a world beyond this universe. A universe that shows the essence of the beings, but it is not understood by the five senses, and it only creates visual images in mind with the help of sight. Therefore, "daydreaming not only helps to recognize one's individual psychology, but also reveals the deep layers of the dreams of the primitive human beings" (Salehi, Gb., 1395, 32). When humans empty many of the ideas from their emotional power in their life and do not show any emotion or feeling toward them, daydreams will affect their behavior with their hidden force, and transform them. In fact, the inner sufferings of man and the unreachable aspirations as a remnant of psychological action are represented unconsciously through dream.

"These occurrences fulfill when the dreams of those who suffer from pain and mental loss, gives them something that the reality hides from them, and that is the happiness and mental health" (Freud, 1963).

In the works of magical realism, "myth", "legend", and "popular beliefs" have a special place, and because folk legends and beliefs are constantly repeated in everyday life, they are driven into the subconscious mind and represented in dream. This style is based on the legends of the South American Indians and they believe in the power of magic in life, hence, the works of this group of writers are full of different myths. For example, at the end of the novel, A Hundred Years of Solitude, as a strange and exotic being born of the Buendia generation, this creature has a tail, and, when it dies, the ants eat its body.

With all the interpretations of the magical realism style, one can say that the human mind understands things and events in the real world and keeps them in the subconscious and processes them in the world of imagination according to the feelings and thoughts of the person, and then creates a new image. In fact, the topic of magical realism is related to psychoanalysis, because people's minds can have different analysis from a fixed phenomenon, like different factories that produce different things from a fixed material. Thus, if we want to further examine this style, we must also examine the writer's personality from the aspect of psychoanalysis so that we can obtain a more accurate result.

Magical realism may be in the division of a school apart from realism, but in fact it is realism itself. Because in magical realism we deal with reality, both the creator and the audience are aware of the events that have occurred, and there is no doubt in their abnormality. 


\section{References}

Ahmadi, B. (1997). Four reports from Tezkirat al-Awliya (1st ed.). Tehran: Markaz.

Al-e Ahmad, J. (1965). Aza'dariy-e Gohar Morad baray-e Ahaliy-e Bayal. Kelk, 12, pp. 9-10.

Allott, M. (2014). Novelist on the Novel (Translated by Ali Mohammad Haghshenas). Tehran: Markaz.

Ann Bows, M. (2014). Magical Realism. Translated by Khat-e Momtad-e Andisheh Institute. Tehran: Neshane.

Asadi Amjad, F. (2007). The Position of Imagination in the Epistemology of Romanticism and Islamic Mysticism. Journal of Foreign Languages Research, 37, pp. 5-24.

Bashlar, G. (2004). Epistemology (Translated by Jalal Sattari). Tehran: Pajouhesh-haye Farhangi.

Bigsby, C. (2016). Dada and Surrealism (Translated by Hasan Afshar). Tehran: Markaz.

Carpentier, A. (2011). The Kingdom of This World (Translated by Kaveh Mirabasi). Tehran: Nika.

Dad, S. (2006). Introduction to Literary Schools. Tehran: Morvarid.

Freud, S. (1963). The Interpretation of reams and Mental Disease (Translated by Iraj Bagherpour). Tehran: Asia.

Grant, D. (2016). Realism (Translated by Hasan Afshar). Tehran: Markaz.

Mahdi Pourmamani, R. (2002). Review and Analysis of Sa'edi's Stories. Tehran: Rouzegar.

Mirsadeghi, J. (1998). Glossary of Art of Story writing. Tehran: Mahnaz.

Niko Bakhte, N. Raminenya, M. (2005). The Investigation of Magical Realism and the Analysis of the Ahl-e Ghargh Novel. Literary Research Quarterly, 8, p. 151.

Parham, S. (1966). Realism and Anti-Realism. Tehran: Nil.

Sa'edi, Gh. (2012). Aza'daran-e Bayal. Tehran: Negah.

Sadeghi, R. (2010). Realism and its Criteria. The Journal of Religion Philosophy, 7(6), p. 17.

Safari, J. Imaniyan, H., Shamsi, H. (2011). The Connection of Mystical Texts with Magical Realism. The Mystical Studies Journal, Faculty of Humanities, Kashan University, 14,

p. 26.

Salehi Mazandarani, M. Gabanchi, N. (2016). Psychoanalytic Criticism of Beliefs and Folklores in the Collection of Aza'daran-e Bayal by Sa'edi. Contemporary Persian Literature, 6(1), p. 31.

Servat, M. (1995). Methodological Realism in Sociology. Journal of Literature and Humanities, 17, p. 22.

Servat, M. (2002). Realism School. Quarterly Journal of Anjoman, 6, p. 24.

Seyyed Hosseini, R. (2002) Literary Schools, Volume I. Tehran: Negah.

Zarinkoub, A. (1983). The Value of Sufi Heritage. Tehran: Amir Kabir. 